\title{
Parylene-Pyrolyzed Carbon For MeMs APPlications
}

\author{
${ }^{I}$ Satoshi Konishi, ${ }^{2}$ Matthieu Liger, ${ }^{2}$ Theodore A. Harder, and ${ }^{2} Y u$-Chong Tai \\ ${ }^{1}$ Department of Mechanical Engineering, Faculty of Science and Engineering, Ritsumeikan University, \\ Kusatsu, Shiga JAPAN \\ ${ }^{2}$ Electrical Engineering, California Institute of Technology, \\ Pasadena, CA USA
}

\begin{abstract}
This paper presents Parylene-pyrolyzed carbon for MEMS applications. Carbons have been used as conductive materials with many promising chemical and thermal properties. This paper focuses on parylene-pyrolyzed carbon to take advantages of its smooth surface deposition and benzene-rich chemical structure. The description of the parylene-pyrolyzed carbon has been tried through evaluations of electrical and mechanical properties in terms of MEMS applications as well as general features. Young's modulus and the resistivity of parylene-pyrolyzed carbon ( $800^{\circ} \mathrm{C}$ pyrolysis) becomes $70 \mathrm{GPa}$ and $0.1 \Omega \mathrm{cm}$, respectively. The relationship between these properties and density will be also discussed.
\end{abstract}

\section{INTRODUCTION}

Carbons have many technical applications due to their electrical, mechanical, thermal, and chemical properties. For example, the graphite is used as electrodes for arc-discharge and high temperature electrolysis. Porous carbons are also attractive as absorbent materials in technologies related to pollution control [1].

Carbons are usually prepared by the pyrolysis of various carbonaceous precursors such as wood, coal, lignite and so on. Polymers can also be used as precursors of pyrolyzed carbons. Recently, Ranganathan et al. reports photoresist-derived carbon for MEMS and Electrochemical applications [2].

We focus on Parylene as the precursor of the pyrolyzed carbon. Parylene, especially Parylene $\mathrm{C}$ has been used in MEMS to take advantages of its useful combination of electrical and mechanical properties and low permeability [3]. Moreover, smooth coating of Parylene film on the surface with topographical variations, such as grooves, cavities, and trenches, can be provided due to CVD deposition at room temperature in vapor phase.

The pyrolysis or carbonization makes it possible to change properties of the precursor material. Regarding to electrical property, dielectric polymers change into conductive carbons through pyrolysis. Therefore, pyrolysis of Parylene $\mathrm{C}$ can be expected to provide a new material for MEMS with taking over several advantages of Parylene based MEMS. Benzene-rich chemical structure of Parylene

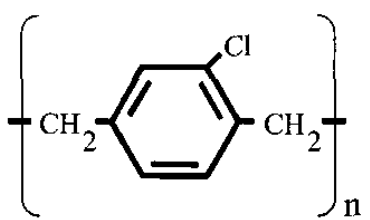

Figure 1: Parylene C chemical structure.

is also attractive for carbonization. So far, the use of Parylene-pyrolyzed carbon as a sacrificial layer was reported by Hui et al. [4]. However, there has been little investigation into the details of pyrolysis of Parylene $C$. It is essential to examine details such as the pyrolysis process and transition of properties through the pyrolysis in order to introduce parylene-pyrolyzed carbon into MEMS applications. Consequently, this paper will explore Parylene-pyrolyzed carbon.

\section{PYROLYSIS OF PARYLENE}

\section{Preliminary investigation}

Pyrolysis of Parylene thin film involves deposition of parylene film on substrates and pyrolysis by heating in the absence of $\mathrm{O}_{2}$. Parylene $\mathrm{C}$ film is employed as a precursor of carbon among members of Parylene $\mathrm{C}$. The chemical structure of Parylene $\mathrm{C}$ is shown in Fig. 1. Parylene $\mathrm{C}$ is modified poly-paraxylylene by the substitution of chlorine atom for one of the aromatic hydrogens.

At first, thermal gravimetric analysis (TGA, $\mathrm{N}_{2}$ atmosphere, $10^{\circ} \mathrm{C} / \mathrm{min}$ ramp rate from 20 to $1200^{\circ} \mathrm{C}$ ) was executed in order to estimate the pyrolysis process of Parylene C. $4 \mu \mathrm{m}$-thick Parylene C films were prepared on various substrates in this work. The thermal gravimetric analysis suggested that there were three major phases of the pyrolysis process of Parylene $\mathrm{C}$ from 20 to $1200^{\circ} \mathrm{C}$. In the first phase, up to $500^{\circ} \mathrm{C}$, slight weight change was observed. It seems to be due to the loss of moisture and some volatiles. The drastic weight loss could be observed between 500 and $600^{\circ} \mathrm{C}$ (the second phase). The main degradation seems to occur in this phase. In the third phase, gradual weight loss continued at elevated temperature. In this experiment, bare Si substrates and Si substrates with $400 \mathrm{~nm}$ thick Ti/Pt film were prepared as substrates for the pyrolysis of Parylene $\mathrm{C}$ in order to estimate catalytic effects of Pt. The result was that the larger weight loss at lower temperature occurred in 


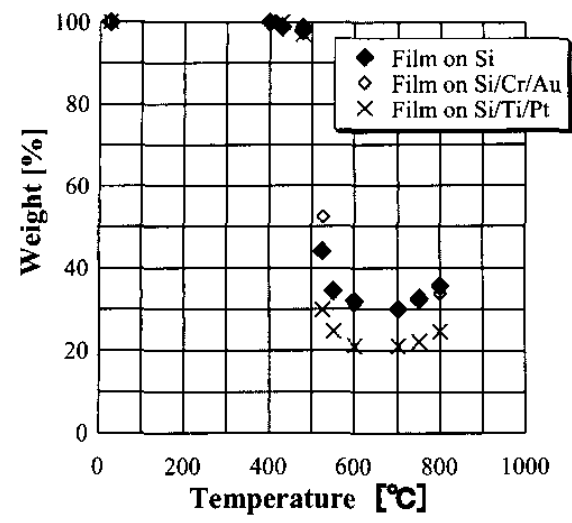

Figure 2: Weight change according pyrolysis temperature $\left(N_{2}, 10^{\circ} \mathrm{C} / \mathrm{min}\right.$ ramp rate).

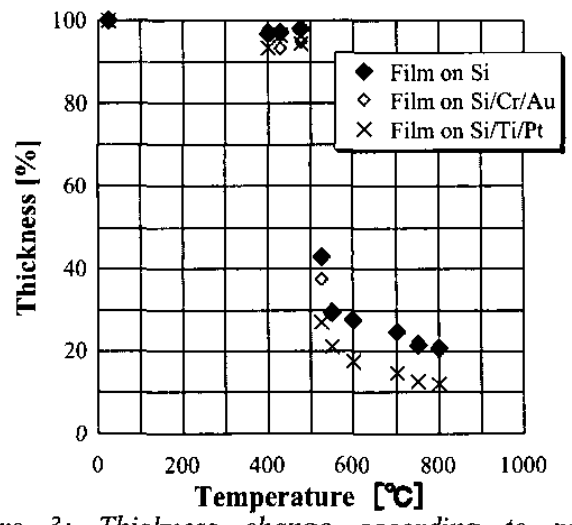

Figure 3: Thickness change according to pyrolysis temperature $\left(\mathrm{N}_{2}, 10^{\circ} \mathrm{C} / \mathrm{min}\right.$ ramp rate)

the pyrolysis of Parylene $\mathrm{C}$ on $\mathrm{Ti} / \mathrm{Pt}$ layer.

Based on the results of preceded TGA, further investigation of changes in weight, thickness, and density through the pyrolysis was accomplished as reported in the following sub-sections. $4 \mu \mathrm{m}$-thick Parylene $\mathrm{C}$ films were deposited on various substrates and pyrolyzed at different temperatures in $\mathrm{N}_{2}$ atmosphere up to $800^{\circ} \mathrm{C}$ with $10^{\circ} \mathrm{C} / \mathrm{min}$ ramp rate in the following experiments. In addition to $\mathrm{Si}$ and $\mathrm{Si} / \mathrm{Ti} / \mathrm{Pt}, \mathrm{Si}$ substrates with $200 \mathrm{~nm}$ thick $\mathrm{Cr} / \mathrm{Au}$ film $(\mathrm{Si} / \mathrm{Cr} / \mathrm{Au})$ were prepared to estimate catalytic effects.

\section{Weight change}

The weight of Parylene $\mathrm{C}$ film was measured before and after the pyrolysis (see Fig. 2). In Fig. 2, weight [\%] as $\mathrm{Y}$-axis means a ratio of weight of pyrolyzed film against its initial weight. The results show good agreements with the preceded TGA except the weight increase at higher temperature. It was found that after exposure to air $\left(20^{\circ} \mathrm{C}\right.$, $47 \%$ in humidity), the weight of carbon film decreased by baking at $100^{\circ} \mathrm{C}$ or in vacuum. The weight then increased once exposed to air again. We believe the weight change was due to moisture absorption and desorption.

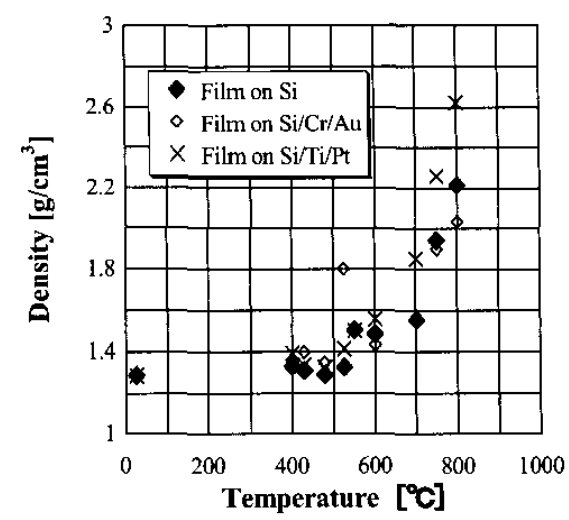

Figure 4: Density vs. Pyrolysis temperature $\left(\mathrm{N}_{2}, 10^{\circ} \mathrm{C} / \mathrm{min}\right.$ ramp rate).

\section{Thickness change}

Regarding the volume change, this work focused on changes in thickness because no obvious changes in lateral dimensions could be observed in our preliminary experiments. Figure 3 shows results of thickness changes of Parylene $\mathrm{C}$ film according to pyrolysis temperature. In Fig. 3 , thickness [\%] as Y-axis means a ratio of thickness of pyrolyzed film against initial thickness of Parylene $\mathrm{C}$ film. Thickness of films was measured by a surface profiler. Three major phases can be recognized as suggested by preceded TGA. Shrinkage of film still continued in the third phase differently from results of weight change. Furthermore, the shrinkage ratio of the film on $\mathrm{Si} / \mathrm{Ti} / \mathrm{Pt}$ dipped from $15 \%$ for $800^{\circ} \mathrm{C}$ pyrolysis, while those of the film on $\mathrm{Si}$ and $\mathrm{Si} / \mathrm{Cr} / \mathrm{Au}$ were about $20 \%$.

\section{Density change}

The properties of carbons are strongly connected with the density [1]. From this point of view, changes in density are evaluated in Fig. 4 based on the results of changes in weight and thickness. There seems to be discontinuity around $500^{\circ} \mathrm{C}$ corresponding to the beginning of the second phase of pyrolysis. The high values of the density at higher temperature in Fig. 4 can be explained by the moisture phenomena as already mentioned. Scattering values between 500 and $600^{\circ} \mathrm{C}$ show a transient phase of the pyrolysis. The results in Fig. 4 will be used to investigate relations between density and various properties in the following sections.

\section{NANOSCOPIC ANALYSIS}

\section{TEM observation}

A carbon film pyrolyzed from Parylene $\mathrm{C}$ at $800^{\circ} \mathrm{C}$ was observed by TEM (see Fig.4). We can see small amounts of graphite-like crystallite structures. The electron- diffraction 


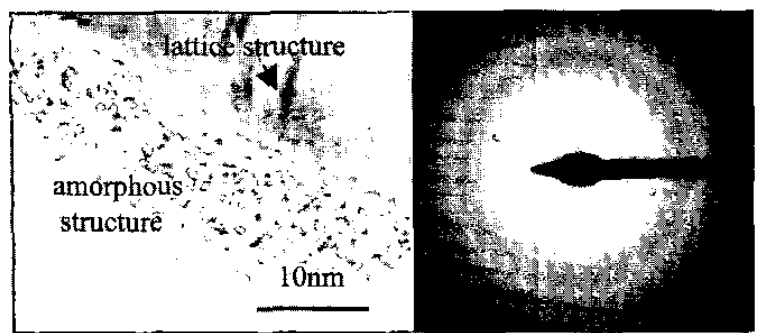

Figure 5: TEM image (left) and electron-diffraction diagram (right) of a carbon film pyrolyzed at $800^{\circ} \mathrm{C}$.

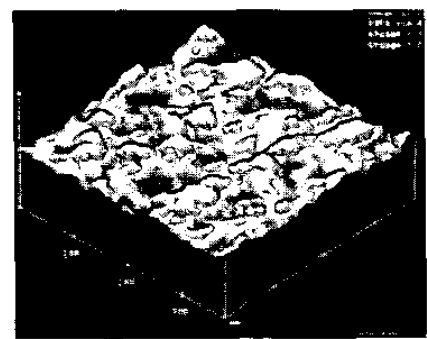

Figure 6: AFM image of parylene-pyrolyzed carbon film surface pyrolyzed at $800^{\circ} \mathrm{C}$.

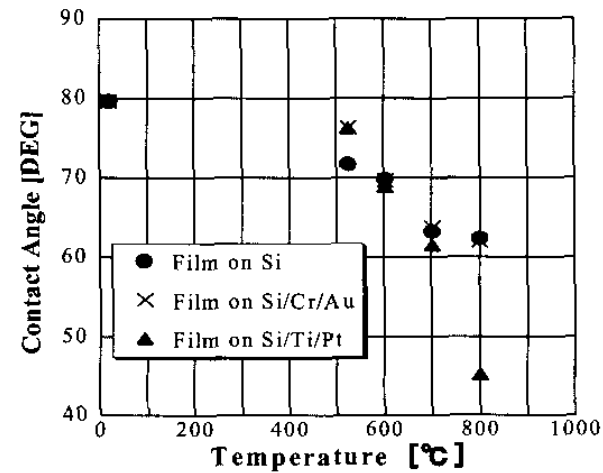

Figure 7: Contact angle according to pyrolysis temperature.

diagram also confirms the existence of (002) plane of graphite (see Fig. 4). However, as a whole, this film is recognized as amorphous carbon.

\section{Surface characterization}

Film surfaces pyrolyzed at various temperatures were observed by the AFM. The AFM image of a film pyrolyzed at $800^{\circ} \mathrm{C}$ is shown in Fig. 6. The AFM observation tell us that surface roughness are within $5 \mathrm{~nm}$ for both films pyrolyzed at $500^{\circ} \mathrm{C}$ and $800^{\circ} \mathrm{C}$. However, a periodical length of roughness for the film at $800^{\circ} \mathrm{C}$ was longer than that for $500^{\circ} \mathrm{C}$. Figure 7 shows measured contact angels according to pyrolysis temperature. The contact angle fell around $500^{\circ} \mathrm{C}$ as well as changes in weight and thickness. The film on Si/Ti/Pt showed a distinguished performance.

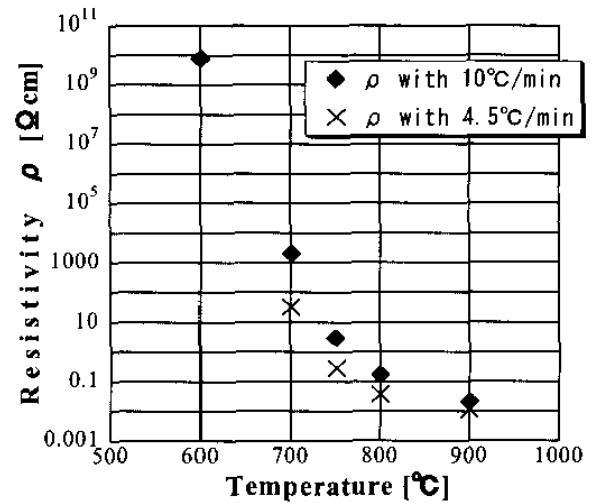

Figure 8: Resistivity of films vs. pyrolysis temperature.

\section{ELECTRICAL PROPERTIES}

The resistivity of Parylene-pyrolyzed carbon depending on pyrolysis temperature is evaluated in Fig. 8. $1 \mu \mathrm{m}$-thick Parylene $\mathrm{C}$ films were pyrolyzed at different temperatures in $\mathrm{N}_{2}$ atmosphere up to $900^{\circ} \mathrm{C}$. The resistivity was calculated from measured sheet resistance and film thickness. The ramp rate of elevated temperature were set at two values $\left(10^{\circ} \mathrm{C} / \mathrm{min}\right.$ and $\left.4.5^{\circ} \mathrm{C} / \mathrm{min}\right)$ and compared each other in this experiment.

Parylene $\mathrm{C}$ films pyrolyzed at a low pyrolysis temperature exhibited high resistivity. The resistivity became less than $1 \times 10^{10} \Omega \mathrm{cm}$ above $600{ }^{\circ} \mathrm{C}$ and decreased to about $1 \times 10^{-2} \Omega \mathrm{cm}$ at $900^{\circ} \mathrm{C}$, which was close to $5 \times 10^{-3} \Omega \mathrm{cm}$ reported for glassy carbons obtained above $1000^{\circ} \mathrm{C}$ [2]. The pyrolysis with a lower ramp rate could provide a lower resistivity.

\section{MECHANICAL PROPERTIES}

Next, the Young's modulus and the stress of Parylene-pyrolyzed carbon were evaluated by the diaphragm load-deflection tests. The deformation of carbon membrane pyrolyzed from $3 \mu \mathrm{m}$-thick Parylene $C$ was measured according to supplied pressure [5]. The carbon membranes were prepared on Si frame structures. Both Young's modulus and the stress are simultaneously obtained by fitting the resulting data to the load-deflection relationship reported by [5]. $3 \mu$ m-thick Parylene $C$ membranes on $\mathrm{Si}$ frame structures as specimens were prepared as follows. $3 \mu \mathrm{m}$-thick Parylene $\mathrm{C}$ film was deposited on a $20 \mu \mathrm{m}$-thick $\mathrm{Si}$ diaphragm structure and released to form Parylene $\mathrm{C}$ membrane by $\mathrm{BrF} 3$ etching of remaining $20 \mu \mathrm{m}$-thick Si layer.

Figure 9 shows calculated Young's modulus and the stress according to pyrolysis temperature. In the calculation, a poisson's ratio was assumed to be 0.4 . The Young's modulus after the pyrolysis became $\sim 50 \mathrm{GPa}$ for $800^{\circ} \mathrm{C}$ pyrolysis $\left(4.5^{\circ} \mathrm{C} / \mathrm{min}\right.$ ramp rate). The stress also increased below $700^{\circ} \mathrm{C}$ but showed a drop at $800^{\circ} \mathrm{C}$. 


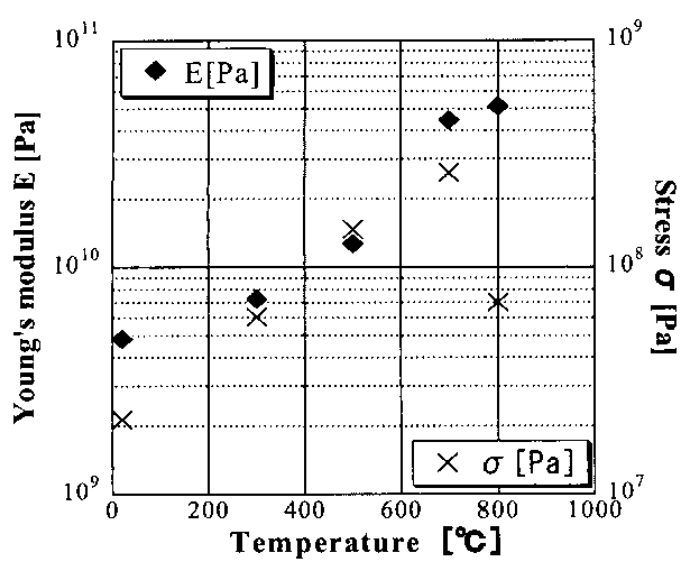

Figure 9: Young's modulus and stress vs. pyrolysis temperature $\left(\mathrm{N}_{2}, 4.5^{\circ} \mathrm{C} / \mathrm{min}\right.$ ramp rate).

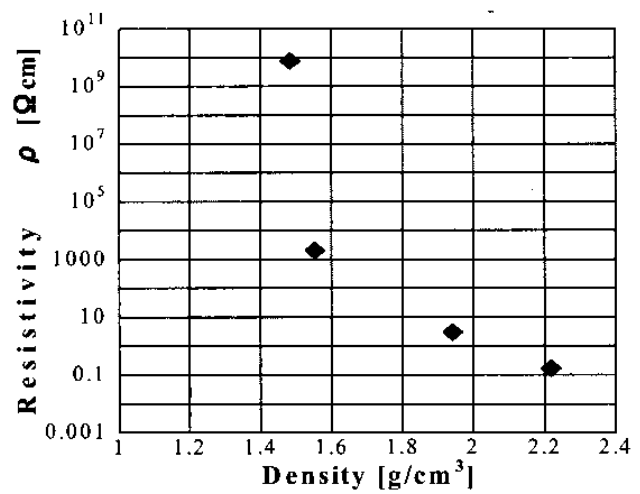

Figure 10: Resistivity vs. density.

\section{DISCUSSION}

First of all, we could see considerable evidences to prove catalytic effects of $\mathrm{Pt}$ for pyrolysis of Parylene $\mathrm{C}$ in all of presented results. These results are presumable because $\mathrm{Pt}$ shows catalytic effects in many other chemical reactions while further investigation into our case is necessary.

Next, relations between properties and density of parylene-pyrolyzed carbon are discussed. Here, density is calculated by using weight of film in air, that is to say, weight with moisture. The relationship between the Young's modulus and the density is shown in Fig. 10. Figure 10 tells that a larger density corresponds to a larger Young's modulus. Moreover, the relationship between the resistivity and the density is also depicted in Fig. 11 that a higher density corresponds to a lower resistivity.

\section{CONCLUSION}

This paper presents Parylene-pyrolyzed carbon for MEMS applications. This work tried to explore the parylene-pyrolyzed carbon through evaluations of electrical

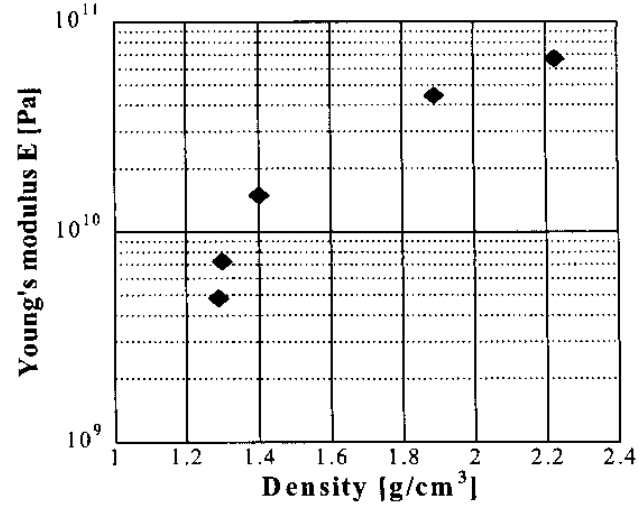

Figure 11: Young's modulus vs. density.

and mechanical properties. Young's modulus and the resistivity of parylene-pyrolyzed carbon $\left(800^{\circ} \mathrm{C}\right.$ pyrolysis) showed $70 \mathrm{GPa}$ and $0.1 \Omega \mathrm{cm}$, respectively. The relations between these properties and density were also discussed.

In addition to reported potential features of this new material, we can obtain carbon MEMS structures for various applications through Parylene micromachining and following pyrolysis [7].

\section{ACKNOLEDGMENTS}

The authors would like to thank the support from NSF CNSE ERC at Caltech and Mr. and Mrs. Boland for their help with TGA, and Mrs. Carol M. Garland for her technical support with TEM observation.

\section{REFERENCES}

[1] W. F. Knippenberg and B. Lersmacher, "Carbon foam", Phillips tech. Rev., vol. 36(4), pp. 93-103, 1976.

[2] S. Ranganathan, R. McCreery, S.M. Majji, and M. Madou, "Photoresist-derived for microelectromechanical Systems and Electrochemical applications", Journal of The Electrochemical Society, 147(1), pp.277-282, 2000.

[3] X-Q Wang, Q. Lin, and Y-C Tai, "A Parylene Micro Check Valve", in DigestTech. Papers MEMS'99 Conference, 1999, pp. 177-182.

[4] E. E. Hui, C. G. Keller, and R. T. Howe, "Carbonized parylene as a conformal sacrificial layer", in DigestTech. Papers 8th Solid-State Sensor and Actuator Workshop, Hilton Head, 1998, pp. 256-260.

[5] O. Tabata, K. Kawahata, S. Sugiyama, and I. Igarashi, "Mechanical property measurements of thin-films using load deflection of composite rectangular membranes", Sensors and Actuators, vol. 20, pp. 135-141, 1989.

[6] T. A. Harder, T-J Yao, Q. He, C-Y Shih, and Y-C Tai, "Residual stress in thin-film Parylene C", in DigestTech. Papers MEMS'02 Conference, 2002, pp. 435-438.

[7] M. Liger, S. Konishi, and Y-C Tai, "A pyrolyzed Parylene uncooled bolometer", in DigestTech. Papers MEMS'04 Conference, 2004. 